\title{
High-dose fenoldopam reduces postoperative neutrophil gelatinase-associated lipocaline and cystatin C levels in pediatric cardiac surgery
}

\author{
Zaccaria Ricci ${ }^{1 *}$, Rosa Luciano ${ }^{2}$, Isabella Favia ${ }^{1}$, Cristiana Garisto ${ }^{1}$, Maurizio Muraca ${ }^{2}$, Stefano Morelli ${ }^{1}$, \\ Luca Di Chiara ${ }^{1}$, Paola Cogo ${ }^{1}$ and Sergio Picardo ${ }^{3}$
}

\begin{abstract}
Introduction: The aim of the study was to evaluate the effects of high-dose fenoldopam, a selective dopamine-1 receptor, on renal function and organ perfusion during cardiopulmonary bypass (CPB) in infants with congenital heart disease $(\mathrm{CHD})$.

Methods: A prospective single-center randomized double-blind controlled trial was conducted in a pediatric cardiac surgery department. We randomized infants younger than 1 year with CHD and biventricular anatomy (with exclusion of isolated ventricular and atrial septal defect) to receive blindly a continuous infusion of fenoldopam at $1 \mathrm{\mu g} / \mathrm{kg} / \mathrm{min}$ or placebo during CPB. Perioperative urinary and plasma levels of neutrophil gelatinase-associated lipocaline (NGAL), cystatin $C(\mathrm{Cys} C)$, and creatinine were measured to assess renal injury after CPB.

Results: We enrolled 80 patients: 40 received fenoldopam (group F) during CPB, and 40 received placebo (group P). A significant increase of urinary NGAL and CysC levels from baseline to intensive care unit (ICU) admission followed by restoration of normal values after 12 hours was observed in both groups. However, urinary NGAL and CysC values were significantly reduced at the end of surgery and 12 hours after ICU admission (UNGAL only) in group F compared with group P ( $P=0.025$ and 0.039 , respectively). Plasma NGAL and CysC tended to increase from baseline to ICU admission in both groups, but they were not significantly different between the two groups. No differences were observed on urinary and plasma creatinine levels and on urine output between the two groups. Acute kidney injury (AKI) incidence in the postoperative period, as indicated by pRIFLE classification (pediatric score indicating Risk, Injury, Failure, Loss of function, and End-stage kidney disease level of renal damage) was $50 \%$ in group $F$ and $72 \%$ in group $P(P=0.08$; odds ratio (OR), 0.38 ; $95 \%$ confidence interval $(C \mathrm{I}), 0.14$ to 1.02$)$. A significant reduction in diuretics (furosemide) and vasodilators (phentolamine) administration was observed in group $\mathrm{F}(\mathrm{P}=0.0085 ; \mathrm{OR}, 0.22 ; 95 \% \mathrm{Cl}, 0.07$ to 0.7$)$.
\end{abstract}

Conclusions: The treatment with high-dose fenoldopam during CPB in pediatric patients undergoing cardiac surgery for CHD with biventricular anatomy significantly decreased urinary levels of NGAL and CysC and reduced the use of diuretics and vasodilators during CPB.

Trial registration: Clinical Trial.Gov NCT00982527.

\footnotetext{
* Correspondence: z.ricci@libero.it

${ }^{1}$ Pediatric Cardiac Anesthesia/Intensive Care Unit, Department of Pediatric Cardiology and Cardiac Surgery, Bambino Gesù Children's Hospital, Piazza S. Onofrio 4, 00165, Rome, Italy

Full list of author information is available at the end of the article
} 


\section{Introduction}

Cardiopulmonary bypass (CPB) represents a unique clinical circumstance in which nearly all aspects of perfusion can be determined by clinicians. So far, considerable controversy relates to appropriate management of physiologic variables during pediatric $\mathrm{CPB}$ (perfusion pressure, bypass flow rates, type of flow (pulsatile versus nonpulsatile), hematocrit values, systemic oxygen delivery $\left(\mathrm{DO}_{2}\right)$, temperature, and acid-base management), resulting in significant differences in how bypass is conducted in cardiac centers [1,2]. In light of this, pathogenesis of $\mathrm{CPB}$-associated renal dysfunction has not been fully elucidated [3,4], and no proven effective prophylaxis or treatment has been established. Acute kidney injury (AKI) after cardiac operations with $\mathrm{CPB}$ is a life-threatening complication, with a reported incidence of up to $36 \%$ [5]. When dialytic treatment is required, the mortality rate may reach $50 \%[6,7]$. Various factors related to the $\mathrm{CPB}$ procedure have been advocated as possible determinants of AKI. They include $\mathrm{CPB}$ duration, red blood cell fragmentation and hemolysis, sublethal red cell damage, resulting in altered rheologic properties, a low perfusion pressure, low pump flow, severe hemodilution, and low $\mathrm{DO}_{2}[8-10]$. In children, after $\mathrm{CPB}$, the combined effects of hypothermia, nonpulsatile perfusion, and reduced mean arterial pressure are involved in the release of angiotensin, renin, catecholamines, and antidiuretic hormone. These circulating substances promote renal vasoconstriction and reduce renal blood flow [11]. Furthermore, the glomerular filtration rate, creatinine clearance, and medullary concentrating capacity are substantially reduced in neonates and young infants, with a net result of increased total body water, increased organ weight (for example, lungs, heart), and greater difficulty with postoperative weaning from ventilatory support [11].

Creatinine, urea nitrogen levels, or urine output are only very late markers for the diagnosis of AKI $[12,13]$. Neutrophil gelatinase-associated lipocalin (NGAL) and cystatin $\mathrm{C}(\mathrm{Cys} C)$ have been recently suggested to be early AKI biomarkers in both adult and pediatric cardiac surgery [14-17]. Different pharmacologic approaches have been experimented with to optimize organ perfusion during $\mathrm{CPB}$. In particular, phentolamine [18], phenoxybenzamine [19], and sodium nitroprusside [20] have been used, because of their vasodilative properties, to manage hypoxic vasoconstriction on $\mathrm{CPB}$, with conflicting results. These agents have rarely been tested with clinical biomarkers of kidney function [21]; typically, diuretics have been the mainstay of promoting renal function and urine flow after pediatric CPB $[22,23]$. Fenoldopam mesylate is a short-acting dopamine-1 (DA-1) agonist with antihypertensive and vasodilative properties [24] that has been used during adult cardiac surgery with conflicting results $[25,26]$. It appears to improve renal function in clinical situations of reduced blood flow by increasing renal blood flow to both the cortex and medullary regions [24]. In pediatric critically ill patients and pediatric cardiac surgery, fenoldopam has been proposed as a nephroprotective agent with additional diuretic properties [27,28]. In light of this, fenoldopam would appear to be the optimal drug during pediatric $\mathrm{CPB}$, to optimize organ perfusion by systemic vasodilation with a potential specific benefit on renal function. Its commonly used clinical dosage ranges from 0.1 to $0.3 \mu \mathrm{g} / \mathrm{kg} / \mathrm{min}[29,30]$. Recently, this agent has been evaluated for controlled hypotension during pediatric abdominal surgery, and the dosage range has been reported effective between 0.8 and $1.2 \mu \mathrm{g} / \mathrm{kg} / \mathrm{min}$. Doses greater than $1.2 \mu \mathrm{g} / \mathrm{kg} / \mathrm{min}$ resulted in increasing heart rate without additional reduction in blood pressure [31].

The present study aimed to evaluate the effects of high-dose fenoldopam infusion $(1 \mu \mathrm{g} / \mathrm{kg} / \mathrm{min})$ on protecting the kidney from $\mathrm{CPB}$-associated AKI, by perioperative measurements of urinary and plasma NGAL and $\mathrm{CysC}$ levels in infants with CHD.

\section{Materials and methods}

\section{Study design}

A single-center prospective double-blind randomized placebo-controlled trial was performed at a tertiary pediatric hospital. The study was approved by the local Ethics Committee ("Comitato Etico per la Sperimentazione Clinica"; approval number, 250) and was registered in the Protocol Registration System (Clinical Trial. Gov Id: NCT00982527).

\section{Objectives}

The primary end point of this study was to assess whether high-dose fenoldopam infusion during $\mathrm{CPB}$ affects renal function by perioperative urinary and plasma NGAL, CysC, and Crea levels measurement. Secondary outcomes were the evaluation of postoperative AKI incidence, as indicated by pRIFLE (pediatric score indicating Risk, Injury, Failure, Loss of function, and End-stage kidney disease level of renal damage) classification [32]; high-dose fenoldopam infusion efficacy was assessed by $\mathrm{CPB}$ perfusion features in the two groups (see later) and by the requirement of diuretics and vasodilators during the $\mathrm{CPB}$ period. Finally, the number of times that the vasodilator infusion was halted because of hypotension (or other side effects) was recorded as a measure of fenoldopam safety. 


\section{Study population}

Inclusion criteria were age younger than 1 year, need for cardiac surgery, and CPB for correction of CHD with biventricular anatomy. Exclusion criteria were surgery for simple ventricular septal defect and atrial septal defect, the presence of preoperative renal dysfunction, predetermined need for deep hypothermic circulatory arrest (DHCA), urgent procedures, and the absence of informed consent. The study was conducted between July 2009 and July 2010.

\section{Randomization procedure}

The allocation sequence was generated by using two computerized random-generation programs stratified by two age groups: (a) neonates (surgery before 30 days after birth) and (b) infants (surgery between 31 and 365 days after birth). To recruit the same proportion of cases, the number of enrolled neonates was limited to 13 per group (32\%), reflecting the institutional rate of neonatal surgery. The patients were evaluated for eligibility the day before surgery, and informed consent was obtained from both parents. After recruitment, the day of operation, sealed envelopes containing the allocation group were opened by a nurse who did not participate in the study or in data collection. The same nurse was in charge of preparing the infusions that were blindly given to the perfusionist. The rest of the nurses and medical staff in the operation room and in the intensive care unit were blinded to group assignment.

\section{Interventions}

All patients received general anesthesia with sevorane inhalation at induction and then midazolam $(0.05 \mathrm{mg} /$ $\mathrm{kg} / \mathrm{h})$, fentanyl $(5 \mu \mathrm{g} / \mathrm{kg} / \mathrm{h})$, and cisatracurium $(0.08 \mathrm{mg} /$ $\mathrm{kg} / \mathrm{h}$ ) infusion for maintenance. CPB was always conducted with open circuits, alpha stat strategy, and blood cardioplegia, targeting CPB flow to $150 \mathrm{ml} / \mathrm{kg} / \mathrm{min}$, hematocrit to $35 \%$, and moderate hypothermia with the temperature ranging between $25^{\circ} \mathrm{C}$ and $32^{\circ} \mathrm{C}$. During $\mathrm{CPB}$, boluses of phentolamine $(0.1 \mu \mathrm{g} / \mathrm{kg})$ were administered when perfusion pressure at full perfusion flow increased over $50 \mathrm{~mm} \mathrm{Hg}$. Patients were blindly allocated to the study group (group F) or to placebo (group P) after anesthesia induction. A continuous infusion of fenoldopam at the dose of $1 \mu \mathrm{g} / \mathrm{kg} / \mathrm{min}$ was administered from $\mathrm{CPB}$ start to $\mathrm{CPB}$ weaning. The drug was always prepared in $25 \mathrm{ml}$ of saline and infused at a rate of $1 \mathrm{ml} / \mathrm{h}$. Group P received a saline solution, infused at the same rate as that of fenoldopam. Infusion was administered directly into the $\mathrm{CPB}$ reservoir. No changes to the intraoperative standard of care were applied during the study period: in particular, fluid balance was controlled by conventional ultrafiltration before $\mathrm{CPB}$ weaning (about $50 \mathrm{ml} / \mathrm{kg}$ of ultrafiltered volume) and by furosemide administration $(1 \mathrm{mg} / \mathrm{kg})$ if the urine output before $\mathrm{CPB}$ weaning was less than $1 \mathrm{ml} / \mathrm{kg} / \mathrm{h}$. The attending anesthesiologist was authorized to interrupt drug infusion due to suspicion of side effects such as excessive hypotension, arrhythmias, or intolerance.

\section{Data collection}

Demographic and baseline characteristics of included patients were collected after enrolment. Urinary output, plasma and urinary levels of creatinine (respectively, pCrea and uCrea), NGAL (respectively, pNGAL and uNGAL), and CysC (respectively, $\mathrm{pCysC}$ and uCysC), blood lactates concentration, superior vena cava oxygen saturation $\left(\mathrm{ScvO}_{2}\right)$ and cerebral near-infrared spectroscopy $\left(\mathrm{rSO}_{2} \mathrm{C}\right)$ value were measured before surgery (t0), at the end of the surgical procedure (t1), and 12 hours after ICU admission (t2). Creatinine levels and urinary output were recorded in the first 96 postoperative days to compute pRIFLE classification.

PCrea and uCrea levels were directly sent to the laboratory and measured with the Jaffe assay (ADVIA Chemistry Systems, Siemens, Munich, Germany). Urine samples for uNGAL and uCysC were collected in dedicated sterile vials, centrifuged at 2,000 rpm, and the supernatant immediately stored at $-80^{\circ} \mathrm{C}$. Blood samples for pNGAL and pCysC were collected in sterile vials containing heparin as an anticoagulant, centrifuged at $3,600 \mathrm{rpm}$, and the supernatant immediately stored at $-80^{\circ} \mathrm{C}$. Plasma and urinary NGAL were measured with a sandwich enzyme-linked immunosorbent assay ( $R \& D$ Systems, Minneapolis, MN, U.S.A.), whereas plasma and urinary cystatin $C$ were evaluated with nephelometry (BN ProSpec; Siemens).

All CPB data (pump flow, minimum temperature, hematocrit, perfusion pressure, furosemide boluses, phentolamine boluses, hemofiltration volume) were prospectively collected by perfusionists, and the average values per each CPB session of every patient were recorded. Average indexed $\mathrm{DO}_{2}$ and systemic vascular resistances (SVRs) were calculated for each patient during $\mathrm{CPB} . \mathrm{DO}_{2}$ was calculated as follows: $\mathrm{CPB}$ pump flow $x$ arterial oxygen content (assumed as hemoglobin concentration $\times$ hemoglobin saturation $\times 1.34+0.003 \times$ arterial oxygen tension). SVRs were calculated as follows: $80 \times(\mathrm{CPB}$ pressure-central venous pressure $) / \mathrm{CPB}$ pump flow. At ICU admission and after 24 hours, in the absence of other direct instrumental measures of cardiac performance, the hemodynamics was evaluated with the mean arterial pressure (MAP) and inotropic score (IS) that indicates different inotropic and vasopressor drug regimens, reflecting dosage of vasoconstrictors/inotropic drugs. IS was calculated as [33]: dopamine $\mu \mathrm{g} / \mathrm{kg} / \mathrm{min} \times$ $1+$ dobutamine $\mu \mathrm{g} / \mathrm{kg} / \mathrm{min} \times 1+$ milrinone $\mu \mathrm{g} / \mathrm{kg} / \mathrm{min}$ $\times 15+$ epinephrine $\mu \mathrm{g} / \mathrm{kg} / \mathrm{min} \times 100$. Survival, length of 
mechanical ventilation, and length of ICU stay also were recorded. Risk-adjusted classification for congenital heart surgery (RACHS-I) was used to compare the severity of surgical risk in the populations [34]. All data were recorded on an Access-based database specifically prepared for this study.

\section{Statistical analysis}

Intention to treat (ITT) was applied, and all enrolled patients were considered for statistical analysis at the end of the study. The $\chi^{2}$ test was used to compare categoric variables. To compare continuous variables, a Mann-Whitney test or Student $t$ test was used, according to the variable distribution. Two-way analysis of variance was used to compare continuous variables over time between the two groups, with the Bonferroni post hoc test for each time point. All data are presented as mean and standard deviation (SD). A $P$ value $<0.05$ was considered significant. Statistical analysis was performed with the GraphPad Prism 5.0 software package (GraphPad Software, San Diego, CA, U.S.A.).

The study was powered on the primary outcome based on a previous landmark study [15]: considering a mean (SD) of uNGAL level, 2 hours after CPB weaning, of $150(90) \mathrm{ng} / \mathrm{ml}$, and a $50 \mathrm{ng} / \mathrm{ml}$ uNGAL difference between the two groups, to achieve an $80 \%$ statistical power with an alpha error of 0.05 ; the number of patients was calculated to be 40 for each group. An interim analysis was planned after enrolment of 40 patients, and a stopping rule was determined in case of major morbidity detected in this phase.

\section{Results}

Figure 1 depicts the flow chart of enrolment phases: in only one case was treatment interrupted by mistake (group P), but data from this patient were analyzed with ITT. Tables 1 and 2 describe baseline characteristics of the two groups that showed similar clinical characteristics.

\section{Primary end points}

In both groups, a significant increase of urinary NGAL and $\mathrm{Cys} C$ levels and a consequent decrease of uCrea was observed from baseline to t1 $(P=0.003,0.03$, and 0.0001 , respectively), followed by a trend to restoration of normal biomarkers values (Table 3). Considering an average CPB length of 200 minutes and an average total surgery time of 400 minutes in both groups (Table 1), it can be estimated that the 11 NGAL measurement was done in all patients about 150 minutes after CPB stop. However, uNGAL values were significantly reduced at $\mathrm{t} 1$ and $\mathrm{t} 2$ in group $\mathrm{F}$ with respect to group P (Figure 2) $(P=0.025)$; furthermore, if a uNGAL cut-off value of $200 \mathrm{ng} / \mathrm{ml}$ was chosen, as previously suggested [35], this

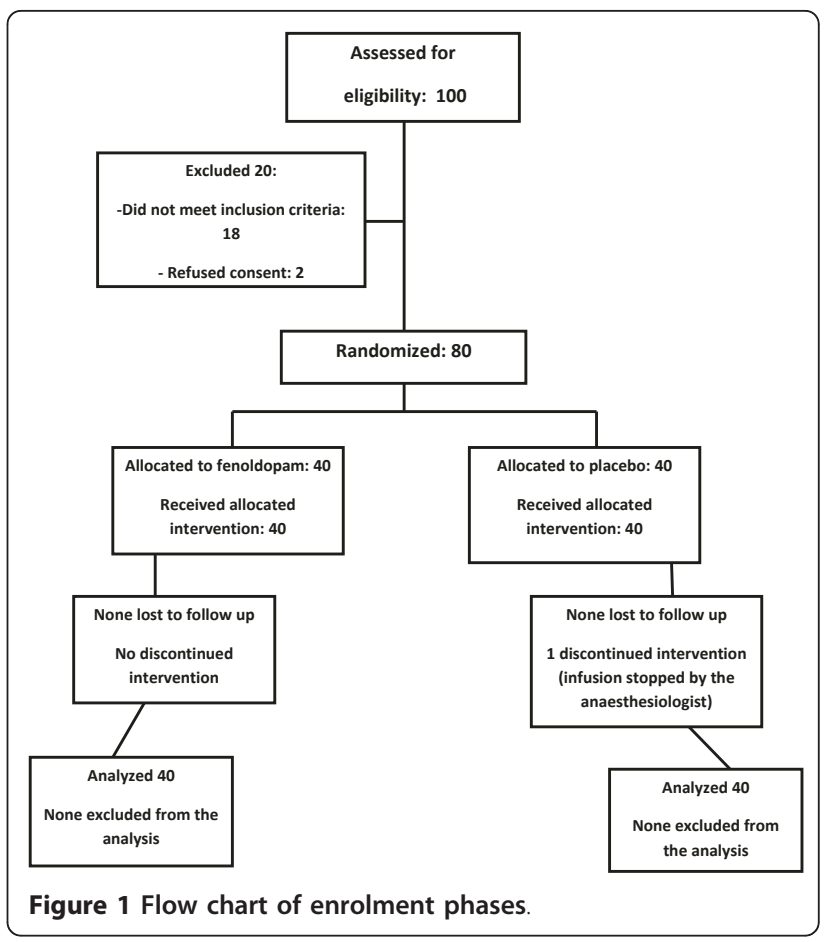

value was reached in significantly more children in group $\mathrm{P}(28 \%)$ with respect to group $\mathrm{F}(5 \%)(P=0.024$; OR, 0.15 ; CI, 0.03 to 0.75$)$. UCysC values were significantly reduced at $\mathrm{t} 1$ in group $\mathrm{F}$ with respect to group $\mathrm{P}$ (Figure 3) $(P=0.039)$; no differences were observed in uCrea levels between the two groups (Table 3). Plasma biomarkers levels (pNGAL, pCysC, and pCrea) significantly increased from to to 11 in both groups $(P=$ 0.0001 for all biomarkers). PNGAL, pCys, and pCrea values were not significantly different between the two groups (Table 3).

Table 1 Demographic characteristics of enrolled patients and main cardiopulmonary bypass (CPB) features

\begin{tabular}{llll}
\hline & Group F & Group P & $P$ \\
\hline Age (days) & $145(156)$ & $139(130)$ & 0.791 \\
Weight $(\mathrm{kg})$ & $5.1(2.0)$ & $5.0(2.2)$ & 0.652 \\
BSA $\left(\mathrm{m}^{2}\right)$ & $0.5(0.2)$ & $0.5(0.3)$ & 0.698 \\
RACHS II score & $2.7(0.6)$ & $2.6(0.6)$ & 0.366 \\
Surgical procedure (minutes) & $390(84)$ & $401(82)$ & 0.599 \\
CPB (minutes) & $212(70)$ & $217(74)$ & 0.905 \\
Crossclamp (minutes) & $119(44)$ & $118(41)$ & 0.923 \\
Prescribed CPB flow (ml/kg/min) & $150(0)$ & $150(0)$ & 0.90 \\
Ht during CPB (\%) & $32(1.9)$ & $33(2.1)$ & 0.237 \\
T min during CPB $\left(^{\circ}\right)$ & $27.1(2.5)$ & $27.8(1.9)$ & 0.418 \\
\hline BSA, body suface area; Ht, hematocrit; & RACHS ${ }^{\circ}$ risk adjustment for
\end{tabular}

BSA, body surface area; $\mathrm{Ht}$, hematocrit; RACHS II, risk adjustment for congenital heart surgery; $\mathrm{T}$, central body temperature. Data are expressed as mean (standard deviation). 
Table 2 Number of neonates and diagnoses of enrolled patients

\begin{tabular}{lll}
\hline Diagnoses & Group F & Group P \\
\hline Number of neonates/total number of patients & $13 / 40$ & $13 / 40$ \\
PA + VSD & 2 & 1 \\
PA + VDS + MAPCAS & 2 & 2 \\
CAVC & 5 & 5 \\
Aortic coarctation and VSD & 2 & 2 \\
ASD-VSD & 2 & 2 \\
Ao supravalvar stenosis & 2 & 2 \\
TOF & 12 & 14 \\
TGA and VSD & 2 & 1 \\
IS-TGA & 9 & 9 \\
TA & 2 & 2 \\
Total & 40 & 40 \\
\hline Ao, aOric ASD, atlapt sef
\end{tabular}

Ao, aortic; ASD, atrial septal defect; IS, intact septum; MAPCAS, multiple aortopulmonary collaterals; PA, pulmonary atresia; TA, truncus arteriosus; TGA, transposition of the great arteries; TOF, tetralogy of Fallot; VSD, ventricular septal defect.

\section{Secondary end points}

AKI incidence, as indicated by pRIFLE classification, was $50 \%$ in group $\mathrm{F}$ and $72 \%$ in group $\mathrm{P}(P=0.08, \mathrm{OR}, 0.38$; $95 \% \mathrm{CI}, 0.14$ to 1.02 ). AKI patients were classified in $90 \%$ of cases in the "Risk" level of severity in both groups, with four "Injury" cases in group F and five in group P. Intra- and postoperative urine output was similar in the two groups (Table 4). Only one patient in group $\mathrm{P}$ required postoperative peritoneal dialysis. Average perfusion pressure was 47.16 (4.72) $\mathrm{mm} \mathrm{Hg}$ in group $\mathrm{F}$ and 49.08 (4.61) $\mathrm{mm} \mathrm{Hg}$ in group $\mathrm{P}(P=$ 0.048 ), whereas $\mathrm{CPB}$ average effective flow rate was 151 (12.5) $\mathrm{ml} / \mathrm{kg} / \mathrm{min}$ in group F and 146.5 (16) $\mathrm{ml} / \mathrm{kg} / \mathrm{min}$ in group $\mathrm{P}(P=0.142)$ (Table 4$) . \mathrm{ScvO}_{2}, \mathrm{rSO}_{2} \mathrm{c}$, blood lactates, mean indexed SVR, and mean indexed $\mathrm{DO}_{2}$ values were not different between groups during the $\mathrm{CPB}$ phase (Table 4); however, we observed a significantly higher number of patients with a $\mathrm{DO}_{2}$ lower than $272 \mathrm{ml} / \mathrm{min} / \mathrm{mq}$ ( $8 \%$ vs. $27 \% ; P=0.048$; OR, $0.27 ; 95 \%$ $\mathrm{CI}, 0.06$ to 0.9 ) in the $\mathrm{F}$ group, a $\mathrm{DO}_{2}$ value recently

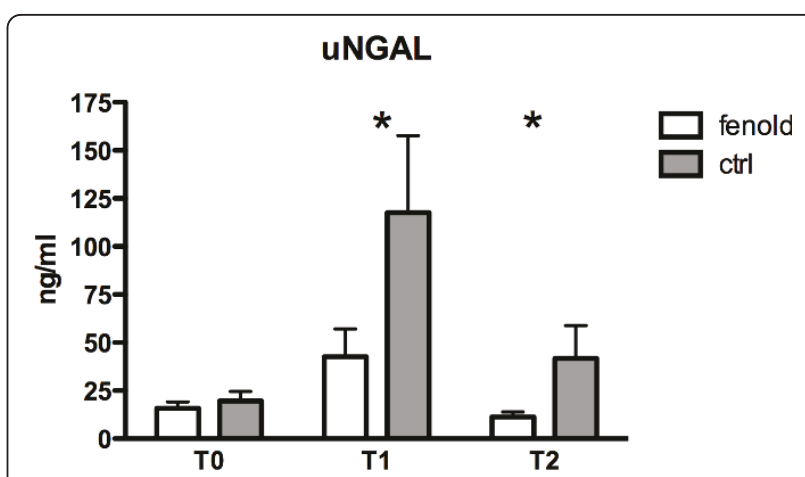

Figure 2 Urinary neutrophil gelatinase-associated lipocaline (uNGAL) levels. A significant increase of UNGAL levels from baseline (t0) to ICU admission ( 11 ) and a consequent decrease after 12 hours (t2) was observed in both groups $(P=0.025)$. However, UNGAL values were significantly reduced in group $\mathrm{F}$ at $\mathrm{t} 1(P=0.02)$ and t2 $(P=0.04)$ compared with group $C\left(^{*}\right)$.

described as the cut-off level below which risk of AKI occurrence is potentially increased [10]. The number of patients that did not receive any phentolamine and/or furosemide boluses during $\mathrm{CPB}$ to target $\mathrm{CPB}$ perfusion pressure or urine flow was significantly higher in group F (58\%) versus group P $(9 \%)(P=0.0085$; OR, $0.22 ; 95 \%$ $\mathrm{CI}, 0.07$ to 0.7$)$. IS did not show significant differences among the two groups either at $\mathrm{CPB}$ weaning or in the postoperative phase (Table 4 ). No side effects were reported in any case of group F. Patients in group F were extubated after 3.8 (3.2) days versus 4.4 (3.7) days for patients in group $\mathrm{P}(P=0.06)$. Length of stay was 5.8 (4.8) days in group $F$ versus 7 (5.3) days in group $P$ $(P=0.055)$. All patients survived to hospital discharge.

\section{Discussion}

Evaluation of organ perfusion and protection during $\mathrm{CPB}$, the gold standard of any $\mathrm{CPB}$ procedure, may depend on how carefully organ function is assessed. In light of this, sensitive and specific biomarkers of ischemic kidney injury might be extremely useful in

Table 3 Renal biomarkers levels in fenoldopam group (F) and placebo group (P) before surgery (t0), at the end of surgical procedure (t1), and 12 hours after intensive care unit admission (t2)

\begin{tabular}{|c|c|c|c|c|c|c|c|}
\hline & TO & & T1 & & $\mathrm{T} 2$ & & $P$ \\
\hline & Group F & Group P & Group F & Group P & Group F & Group P & \\
\hline uNGAL (ng/ml) & $37.2(84.5)$ & $37(232)$ & $94.2(240)^{a}$ & $140(249)$ & $20.4(15.7)^{a}$ & $57(105)$ & 0.025 \\
\hline pNGAL (ng/ml) & $62(33)$ & $66(31)$ & $88(38)$ & $96(40)$ & $93(45)$ & $99(41)$ & 0.253 \\
\hline uCys C (mg/l) & $0.12(0.2)$ & $0.08(0.06)$ & $0.16(0.3)^{\mathrm{a}}$ & $0.22(0.5)$ & $0.06(0.04)$ & $0.09(0.13)$ & 0.039 \\
\hline pCys C (mg/l) & $1.0(0.3)$ & $1.1(0.3)$ & $0.96(0.28)$ & $1.0(0.25)$ & $1.19(0.3)$ & $1.3(0.3)$ & 0.344 \\
\hline pCrea (mg/dl) & $0.51(0.15)$ & $0.46(0.16)$ & $0.63(0.17)$ & $0.64(0.13)$ & $0.64(0.2)$ & $0.62(0.2)$ & 0.114 \\
\hline uCrea (mg/dl) & $53.5(37.4)$ & $49.6(33.7)$ & $8.5(5.5)$ & $8.5(7.6)$ & $26.4(23.4)$ & $26.4(23.7)$ & 0.707 \\
\hline
\end{tabular}

Mean (standard deviation) levels of plasma and urinary levels of creatinine (respectively, pCrea and uCrea), neutrophil gelatinase-associated lipocalin (respectively pNGAL and UNGAL), and cystatine-C (respectively, pCysC and uCysC) are reported. ${ }^{a}$ Significant differences by Bonferroni post test of ANOVA. We found a significant difference between groups of uNGAL levels at $\mathrm{t} 1(P=0.02)$ and $\mathrm{t} 2(P=0.04)$ and of uCysC levels at $\mathrm{t} 1(P=0.04)$. Data are expressed as mean (standard deviation). 


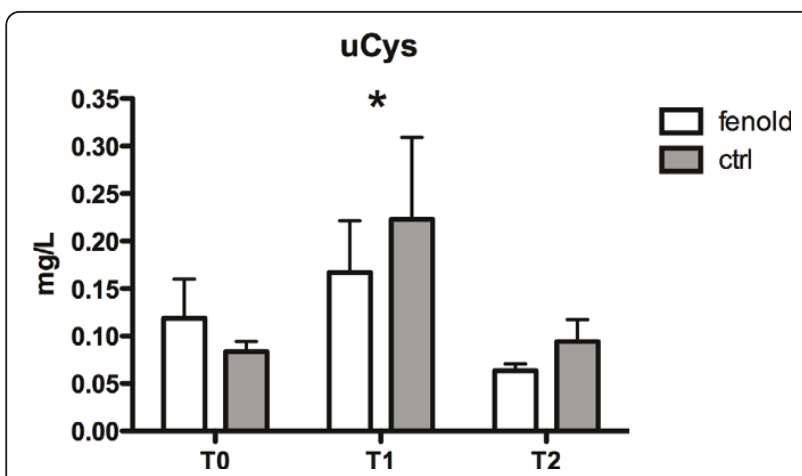

Figure $\mathbf{3}$ Urinary cystatin-C (uCysC) levels. A significant increase of UCysC levels from baseline to ICU admission and a subsequent decrease after 12 hours was observed in both groups $(P=0.039)$. UCys $C$ values were significantly reduced at t1 $(P=0.04)$ in group $F$ with respect to group $C\left(^{*}\right)$.

evaluating the efficacy of a CPB strategy on the optimization of renal perfusion. In our study, all enrolled patients experienced NGAL, CysC, (and pCrea) relative increase after $\mathrm{CPB}$ with respect to their baseline value, even when such increments did not reach a frankly pathologic cut-off. Nevertheless, this increase was significantly blunted by fenoldopam. Furthermore, fewer patients in group $\mathrm{F}$ experienced an increase of uNGAL over $200 \mathrm{ng} / \mathrm{ml}$, recently identified as a reliable cut-off marker of renal function [35]. It is possible that in most cases, such renal impairment would have remained undiagnosed, considering the few patients requiring renal replacement. In a recent large pooled analysis, Haase and co-workers [36] confirmed that a progressive increase in length of hospital stay is present with increasing biomarkers levels, even in patients with normal creatinine. However, analysis of AKI incidence in our population surprisingly showed that $50 \%$ of patients in group $\mathrm{F}$ and more than $70 \%$ in group $\mathrm{P}$ were classified in one of the pRIFLE classes.

Adequate systemic $\mathrm{DO}_{2}$ during $\mathrm{CPB}$ may be one of the most important determinants of "optimal" perfusion, and it has been shown to be an independent risk factor for cardiac surgery-associated AKI [10]. In a cohort of 1,048 coronary artery bypass graft (CABG) patients, Ranucci et al. [10] evidenced that an indexed $\mathrm{DO}_{2}$ of $272 \mathrm{ml} / \mathrm{min} / \mathrm{m}^{2}$ was a critical value for development for postoperative renal dysfunction in a large cohort of adult patients. During our study, only $8 \%$ of patients in group F (vs. 27\% in group P) reached such a critical level of indexed $\mathrm{DO}_{2}$. It must be remarked that it is currently unknown whether such results might be applicable to the pediatric setting. However, during pediatric $\mathrm{CPB}$, management of vascular resistances plays a key role to deliver adequate and homogeneous whole-body $\mathrm{DO}_{2}$, so a variety of vasodilator agents have been studied for their effects on tissue perfusion during CPB. Phentolamine is a nonselective competitive alpha1 and alpha2 catecholamine-receptor blocker. It has a half-life of 19 minutes, and it is eliminated mainly by the kidneys. Through postsynaptic receptor inhibition, it has a vasodilating and hypotensive effect that can improve cardiovascular parameters during CPB [17]. More recently, fenoldopam has been used during adult cardiac surgery. The association between its vasodilating proprieties with its specificity on renal (and splanchnic) perfusion makes it a potentially ideal agent during pediatric $\mathrm{CPB}$. Interestingly, in a recent RCT on adult cardiac surgery, patients were randomly assigned to receive the

Table 4 Average (standard deviation) levels found

\begin{tabular}{|c|c|c|c|c|c|c|c|}
\hline & \multicolumn{2}{|l|}{ TO } & \multicolumn{2}{|l|}{$\mathrm{T} 1$} & \multicolumn{2}{|l|}{$\mathrm{T} 2$} & \multirow[t]{2}{*}{$P$} \\
\hline & Group F & Group P & Group F & Group P & Group F & Group P & \\
\hline$\overline{\mathrm{MAP}(\mathrm{mm} \mathrm{Hg})}$ & $53.1(8.6)$ & $54.6(10.7)$ & $62.9(10.9)$ & $64.6(14.0)$ & $65.7(13.0)$ & $62.5(11.2)$ & 0.99 \\
\hline IS & $0(0)$ & $0(0)$ & $9.5(5)$ & $12.7(9)$ & $8.7(5)$ & $9.1(6)$ & 0.374 \\
\hline Lactates (mM) & $1.0(0.5)$ & $0.9(0.5)$ & $3.3(2.4)$ & $3.8(2.5)$ & $1.6(1.0)$ & $1.9(1.5)$ & 0.433 \\
\hline $\mathrm{ScvO}_{2}(\%)$ & $59.6(16.6)$ & $59.8(17.3)$ & $58.1(15.0)$ & $59.0(15.3)$ & $61.9(16.0)$ & $56.7(14.8)$ & 0.555 \\
\hline $\mathrm{rSO}_{2} \mathrm{C}(\%)$ & $58.0(12.1)$ & $58.6(10.9)$ & $59.8(15.3)$ & $56.9(14.7)$ & $64.0(9.3)$ & $63.5(11.3)$ & 0.590 \\
\hline \multirow{3}{*}{ Diuresis $(\mathrm{ml} / \mathrm{kg} / \mathrm{h})$} & $5.9(5.2)$ & $6.9(6.3)$ & $7.5(6.7)$ & $6.8(4.7)$ & $5.0(2.5)$ & $4.7(2.8)$ & 0.340 \\
\hline & CPB phase & & & & & & \\
\hline & Group F & & & Group P & & & \\
\hline CPB press ${ }^{\mathrm{a}}(\mathrm{mm} \mathrm{Hg})$ & $47.2(4.7)$ & & & $49.0(4.6)$ & & & 0.048 \\
\hline Effective CPB flow ${ }^{\mathrm{a}}(\mathrm{ml} / \mathrm{kg} / \mathrm{min})$ & $151(12.5)$ & & & $146.5(16)$ & & & 0.142 \\
\hline $\begin{array}{l}\mathrm{IDO}_{2}^{\mathrm{a}} \\
\left(\mathrm{ml} \mathrm{O}_{2} / \mathrm{min} / \mathrm{m}^{2}\right)\end{array}$ & $342.4(50.1)$ & & & $331.7(58.7)$ & & & 0.460 \\
\hline $\operatorname{ISVR}^{\mathrm{a}}\left(\mathrm{dyn} \cdot \mathrm{s} \cdot \mathrm{cm}^{-5} / \mathrm{m}^{2}\right)$ & $404.9(59.8)$ & & & $423.5(97.2)$ & & & 0.502 \\
\hline
\end{tabular}

Levels of mean arterial pressure (MAP), lactates, central venous saturation $\left(\mathrm{ScvO}_{2}\right)$, cerebral near infrared spectroscopy $\left(\mathrm{rSO}{ }_{2} \mathrm{c}\right)$, urine output, cardiopulmonary bypass (CPB) pressure, indexed oxygen delivery $\left(\mathrm{IDO}_{2}\right)$, and indexed systemic vascular resistances (ISVR) collected before surgery (t0), at the end of the surgical procedure (t1) and 12 hours after intensive care unit admission (t2). Diuresis at $\mathrm{t} 1$ includes intraoperative urine output. ${ }^{\mathrm{a}}$ Data collected exclusively during CPB phase. Data are expressed as mean (standard deviation). 
short half-life drug fenoldopam $(0.1 \mu / \mathrm{kg} / \mathrm{min})$ or placebo [37]. Fenoldopam infusion started at the onset of $\mathrm{CPB}$ and was maintained for the first 12 postoperative hours. Patients in the fenoldopam group had higher $\mathrm{DO}_{2}$ during $\mathrm{CPB}$, higher pump flow rate, and a significantly lower perfusion pressure, although this parameter was still within the normal range. Blood lactate concentrations during $\mathrm{CPB}$ were similar in the two groups. Urine output during and after $\mathrm{CPB}$ did not differ between groups, nor did the renal function parameters. A significantly higher rate of AKI was found in the placebo group (10\% vs. 0) [37].

In our study, during CPB, we administered $0.1 \mathrm{mg} / \mathrm{kg}$ phentolamine boluses in case of high perfusion pressure at full perfusion flow. Similar to the Ranucci et al. trial [37], average $\mathrm{DO}_{2}$ levels, $\mathrm{SVR}, \mathrm{ScvO}_{2}, \mathrm{rSO}_{2} \mathrm{c}$, and blood lactates suggested adequate perfusion in both groups. However, in the fenoldopam group, CPB average perfusion pressure was significantly lower, and the average effective $\mathrm{CPB}$ flow tended to be higher (even higher than the prescribed flow of $150 \mathrm{ml} / \mathrm{kg} / \mathrm{min}$ ). We speculate that a continuous fenoldopam infusion warranted a constant systemic vasodilatation and a better overall perfusion than did repeated phentolamine boluses. This assumption may be supported by the renal biomarker difference, and by the fact that patients in group $\mathrm{F}$ required a lower amount of phentolamine and furosemide administration: this effect might be explained, again, by the optimization of renal (and splanchnic) perfusion during $\mathrm{CPB}$. It must be remarked, however, that these speculations derive from an associative analysis, because phentolamine/furosemide administration was not limited by study protocol. This trial had several strengths and pitfalls. This was the first RCT examining the use of high-dose fenoldopam during CPB in pediatric surgery. The trial was stratified by age and included an homogeneous cohort of young babies who might have different $\mathrm{CPB}$ physiopathology and systemic vascular resistances from those of older children. The limits of this trial were that it was a single-center study, limiting its external validity; it was not powered for postoperative pediatric AKI; a cost/benefit analysis was not performed; palliative surgery, DHCA procedures, and RACHS 5 and 6 were excluded by protocol from enrolment, whereas in these kinds of patients, the impact of perfusion optimization on organ protection would have been potentially magnified; finally, only indices of renal function were strictly monitored and eventually considered as surrogates of splanchnic perfusion. However, it must be remarked that this was an initial experience, and the potential feasibility of high-dose fenoldopam during pediatric $\mathrm{CPB}$ has not been evaluated before; therefore, a sensitive and specific biomarker of renal ischemic injury was targeted as the primary objective instead of cardiac surgery-associated AKI or other organs dysfunction, due to the specific fenoldopam action on renal perfusion: this primary outcome allowed us to reduce sample size and costs of the trial; furthermore, the administration of the drug was limited to a "safer" cohort of CHD, at lower risk of perioperative morbidity and unstable hemodynamics. After such results, the extended application of high-dose fenoldopam to patients with univentricular anatomy and higher RACHS score is currently under evaluation in our institution.

\section{Conclusions}

In conclusion, high-dose fenoldopam during CPB in pediatric cardiac surgery appeared to be safe and potentially nephroprotective. The routine prophylactic use of this agent during $\mathrm{CPB}$ cannot be recommended on the basis of this trial, especially before an accurate cost/benefit analysis is performed; however, our data encourage further research in this field.

\section{Key messages}

- Cardiopulmonary bypass during pediatric cardiac surgery induces a significant increase of urinary and plasmatic NGAL and CysC levels from baseline to ICU admission followed by restoration of normal values after 12 hours.

- Urinary NGAL and CysC increase is significantly reduced at the end of surgery and 12 hours after ICU admission by the infusion of $1 \mu \mathrm{g} / \mathrm{kg} / \mathrm{min}$ of fenoldopam.

- Fenoldopam infusion may improve systemic vasodilation and renal perfusion during CPB: compared with controls, a significant reduction in furosemide and phentolamine requirement during $\mathrm{CPB}$ was observed in patients receiving fenoldopam.

- AKI incidence, as indicated by pRIFLE classification after pediatric cardiac surgery, is high. According to our data, it was $50 \%$ in patients receiving fenoldopam and $72 \%$ in controls.

\section{Abbreviations}

AKI: acute kidney injury; CHD: congenital heart disease; CPB: cardiopulmonary bypass; Crea: creatinine; CysC: cystatin C; DHCA: deep hypothermic circulatory arrest; $\mathrm{DO}_{2}$ : oxygen delivery; ICU: intensive care unit; IS: inotropic score; MAP: mean arterial pressure; NGAL: neutrophil gelatinaseassociated lipocaline; pRIFLE: pediatric RIFLE (Risk: Injury: Failure: Loss of

function: End-stage kidney disease); $\mathrm{rSO}_{2} \mathrm{C}$ : cerebral near-infrared spectroscopy; $\mathrm{ScVO}_{2}$ : superior vena cava oxygen saturation; SVR: systemic vascular resistance.

\section{Acknowledgements}

We are grateful for the fulfilment of this project to our perfusionsists: Ondina La Salvia, Rita Carbonari, Fiamma Michetti, Alexandra Gach, Giulia Bravetti, and Tamara Cantore. 


\section{Author details}

${ }^{1}$ Pediatric Cardiac Anesthesia/Intensive Care Unit, Department of Pediatric Cardiology and Cardiac Surgery, Bambino Gesù Children's Hospital, Piazza S. Onofrio 4, 00165, Rome, Italy. ${ }^{2}$ Clinical Laboratory, Department of Clinical Medicine, Bambino Gesù Children's Hospital, Piazza S. Onofrio 4, 00165, Rome, Italy. ${ }^{3}$ Emergency Department Unit, Bambino Gesù Children's Hospital, Piazza S. Onofrio 4, 00165, Rome, Italy.

\section{Authors' contributions}

ZR contributed to the idea and the design of the study, was responsible for acquisition of patient data, collected and analyzed the data, and wrote the manuscript. RL performed analyses, contributed to the drafts of the manuscript, and gave final approval to the present manuscript. IF, CG, SM, and LDC contributed to data collection, assisted in patient recruitment, and gave final approval to the present manuscript. MM contributed to study conception, supervised analyses performance, and gave final approval to the present manuscript. SP participated in study conception, design, and coordination, helped in manuscript revision, and gave final approval to the present manuscript. PC helped to draft the manuscript, participated in interpretation of the data, supervised the final manuscript version, and gave final approval to the present manuscript.

\section{Competing interests}

The authors declare that they have no competing interests.

Received: 13 April 2011 Revised: 17 May 2011 Accepted: 29 June 2011 Published: 29 June 2011

\section{References}

1. Miller A, Lu CK, Wang S, Umstead TM, Freeman WM, Vrana K, Yang S, Myers JL, Phelps DS, Zahn JD, Undar A: Pediatric cardiopulmonary bypass circuits: a review of studies conducted at the Penn State Pediatric Cardiac Research Laboratories. J Extra Corpor Technol 2009, 41:P50-P58.

2. Murphy GS, Hessel EA, Groom RC: Optimal perfusion during cardiopulmonary bypass: an evidence-based approach. Anesth Analg 2009, 108:1394-1417.

3. Chiravuri SD, Riegger LQ, Christensen R, Butler RR, Malviya S, Tait AR, Voepel-Lewis T: Factors associated with acute kidney injury or failure in children undergoing cardiopulmonary bypass: a case-controlled study. Paediatr Anaesth 2011, 21:880-886.

4. Sirvinskas E, Andrejaitiene J, Raliene L, Nasvytis L, Karbonskiene A, Pilvinis V, Sakalauskas J: Cardiopulmonary bypass management and acute renal failure: risk factors and prognosis. Perfusion 2008, 23:323-327.

5. Zappitelli M, Bernier PL, Saczkowski RS, Tchervenkov Cl, Gottesman R, Dancea A, Hyder A, Alkandari O: A small post-operative rise in serum creatinine predicts acute kidney injury in children undergoing cardiac surgery. Kidney Int 2009, 76:885-892.

6. Fleming F, Bohn D, Edwards H, Cox P, Geary D, McCrindle BW, Williams WG: Renal replacement therapy after repair of congenital heart disease in children: a comparison of hemofiltration and peritoneal dialysis. J Thorac Cardiovasc Surg 1995, 109:322-331.

7. Symons JM, Chua AN, Somers MJ, Baum MA, Bunchman TE, Benfield MR, Brophy PD, Blowey D, Fortenberry JD, Chand D, Flores FX, Hackbarth R, Alexander SR, Mahan J, McBryde KD, Goldstein SL: Demographic characteristics of pediatric continuous renal replacement therapy: a report of the prospective pediatric continuous renal replacement therapy registry. Clin J Am Soc Nephrol 2007, 2:732-738.

8. Sirvinskas E, Andrejaitiene J, Raliene L, Nasvytis L, Karbonskiene A, Pilvinis V, Sakalauskas J: Cardiopulmonary bypass management and acute renal failure: risk factors and prognosis. Perfusion 2008, 23:323-327.

9. Haase M, Bellomo R, Haase-Fielitz A: Novel biomarkers, oxidative stress, and the role of labile iron toxicity in cardiopulmonary bypass-associated acute kidney injury. J Am Coll Cardiol 2010, 55:2024-2033.

10. Ranucci M, Romitti F, Isgrò G, Cotza M, Brozzi S, Boncilli A, Ditta A: Oxygen delivery during cardiopulmonary bypass and acute renal failure after coronary operations. Ann Thorac Surg 2005, 80:2213-2220.

11. Markowitz SD, Greeley WJ: Cardiopulmonary bypass. In Anesthesia for Congenital Heart Disease.. 1 edition. Edited by: Andropulos DB, Layer SA, Russel IA. Boston, Mass., USA: Blackwell Publishing; 2005:64-81.
12. Al-Ismaili Z, Palijan A, Zappitelli M: Biomarkers of acute kidney injury in children: discovery, evaluation, and clinical application. Pediatr Nephrol 2011, 26:29-40.

13. Uchino S: Creatinine. Curr Opin Crit Care 2010.

14. Haase-Fielitz A, Bellomo R, Devarajan P, Story D, Matalanis G, Dragun D, Haase M: Novel and conventional serum biomarkers predicting acute kidney injury in adult cardiac surgery: a prospective cohort study. Crit Care Med 2009, 37:553-560.

15. Mishra J, Dent C, Tarabishi R, Mitsnefes MM, Ma Q, Kelly C, Ruff SM, Zahedi K, Shao M, Bean J, Mori K, Barasch J, Devarajan P: Neutrophil gelatinase-associated lipocalin (NGAL) as a biomarker for acute renal injury after cardiac surgery. Lancet 2005, 365:1231-1238.

16. Haase M, Bellomo R, Haase-Fielitz A: Neutrophil gelatinase-associated lipocalin. Curr Opin Crit Care 2010.

17. Bagshaw SM, Bellomo R: Cystatin C in acute kidney injury. Curr Opin Crit Care 2010.

18. Köner O, Tekin S, Köner A, Soybir N, Seren S, Karaoglu K: Effects of phentolamine on tissue perfusion in pediatric cardiac surgery. J Cardiothorac Vasc Anesth 1999, 13:191-197.

19. Tweddell JS, Hoffman GM, Fedderly RT, Berger S, Thomas JP Jr, Ghanayem NS, Kessel MW, Litwin SB: Phenoxybenzamine improves systemic oxygen delivery after the Norwood procedure. Ann Thorac Surg 1999, 67:161-167.

20. Tuğrul M, Pembeci $K$, Camci E, Ozkan T, Telci L: Comparison of the effects of sodium nitroprusside and isoflurane during rewarming on cardiopulmonary bypass. J Cardiothorac Vasc Anesth 1997, 11:712-717.

21. Kaya K, Oğuz M, Akar AR, Durdu S, Aslan A, Erturk S, Taşöz R, Ozyurda U: The effect of sodium nitroprusside infusion on renal function during reperfusion period in patients undergoing coronary artery bypass grafting: a prospective randomized clinical trial. Eur J Cardiothorac Surg 2007, 31:290-297.

22. Picca S, Ricci Z, Picardo S: Acute kidney injury in an infant after cardiopulmonary bypass. Semin Nephrol 2008, 28:470-476.

23. van der Vorst MM, Ruys-Dudok van Heel I, Kist-van Holthe JE, den Hartigh J, Schoemaker RC, Cohen AF, Burggraaf J: Continuous intravenous furosemide in haemodynamically unstable children after cardiac surgery. Intensive Care Med 2001, 27:711-715.

24. Tumlin JA: Impaired blood flow in acute kidney injury: pathophysiology and potential efficacy of intrarenal vasodilator therapy. Curr Opin Crit Care 2009, 15:514-519.

25. Bove T, Landoni G, Calabrò MG, Aletti G, Marino G, Cerchierini E, Crescenzi G, Zangrillo A: Renoprotective action of fenoldopam in highrisk patients undergoing cardiac surgery: a prospective, double-blind, randomized clinical trial. Circulation 2005, 111:3230-3235.

26. Landoni G, Biondi-Zoccai GG, Marino G, Bove T, Fochi O, Maj G, Calabrò MG, Sheiban I, Tumlin JA, Ranucci M, Zangrillo A: Fenoldopam reduces the need for renal replacement therapy and in-hospital death in cardiovascular surgery: a meta-analysis. I Cardiothorac Vasc Anesth 2008, 22:27-33.

27. Moffett BS, Mott AR, Nelson DP, Goldstein SL, Jefferies JL: Renal effects of fenoldopam in critically ill pediatric patients: a retrospective review. Pediatr Crit Care Med 2008, 9:403-406.

28. Costello JM, Thiagarajan RR, Dionne RE, Allan CK, Booth KL, Burmester M, Wessel DL, Laussen PC: Initial experience with fenoldopam after cardiac surgery in neonates with an insufficient response to conventional diuretics. Pediatr Crit Care Med 2006, 7:28-33.

29. Meco M, Cirri S: The effect of various fenoldopam doses on renal perfusion in patients undergoing cardiac surgery. Ann Thorac Surg 2010, 89:497-550.

30. Ricci Z, Stazi GV, Di Chiara L, Morelli S, Vitale V, Giorni C, Ronco C, Picardo S: Fenoldopam in newborn patients undergoing cardiopulmonary bypass: controlled clinical trial. Interact Cardiovasc Thorac Surg 2008, 7:1049-1053.

31. Hammer GB, Verghese ST, Drover DR, Yaster M, Tobin JR: Pharmacokinetics and pharmacodynamics of fenoldopam mesylate for blood pressure control in pediatric patients. BMC Anesthesiol 2008, 6:8-16.

32. Akcan-Arikan A, Zappitelli M, Loftis LL, Washburn KK, Jefferson LS, Goldstein SL: Modified RIFLE criteria in critically ill children with acute kidney injury. Kidney Int 2007, 71:1028-1035.

33. Shore $S$, Nelson D, Pearl J, Manning P, Wong H, Shanley T, Keyser T, Schwartz S: Usefulness of corticosteroid therapy in decreasing 
epinephrine requirements in critically ill infants with congenital heart disease. Am J Cardiol 2001, 88:591-594.

34. Jenkins KJ: Risk adjustment for congenital heart surgery: the RACHS-1 method. Semin Thorac Cardiovasc Surg Pediatr Card Surg Annu 2004, 7:180-184.

35. Haase M, Bellomo R, Devarajan P, Schlattmann P, Haase-Fielitz A, for the NGAL Meta-analysis Investigator Group: Accuracy of neutrophil gelatinaseassociated lipocalin (NGAL) in diagnosis and prognosis in acute kidney injury: a systematic review and meta-analysis. Am J Kidney Dis 2009, 54:1012-1024.

36. Haase M, Devarajan P, Haase-Fielitz A, Bellomo R, Cruz DN, Wagener G, Krawczeski CD, Koyner JL, Murray P, Zappitelli M, Goldstein SL, Makris K, Ronco C, Martensson J, Martling CR, Venge P, Siew E, Ware LB, Ikizler TA, Mertens PR: The outcome of neutrophil gelatinase-associated lipocalinpositive subclinical acute kidney injury: a multicenter pooled analysis of prospective studies. J Am Coll Cardiol 2011, 57:1752-1761.

37. Ranucci M, De Benedetti D, Bianchini C, Castelvecchio S, Ballotta A, Frigiola A, Menicanti L: Effects of fenoldopam infusion in complex cardiac surgical operations: a prospective, randomized, double-blind, placebocontrolled study. Minerva Anestesiol 2010, 76:249-259.

doi:10.1186/cc10295

Cite this article as: Ricci et al:: High-dose fenoldopam reduces

postoperative neutrophil gelatinase-associated lipocaline and cystatin C levels in pediatric cardiac surgery. Critical Care 2011 15:R160.

\section{Submit your next manuscript to BioMed Central} and take full advantage of:

- Convenient online submission

- Thorough peer review

- No space constraints or color figure charges

- Immediate publication on acceptance

- Inclusion in PubMed, CAS, Scopus and Google Scholar

- Research which is freely available for redistribution

Submit your manuscript at www.biomedcentral.com/submit
Biomed Central 